\title{
Implementation Strategy and Effect Analysis on Subject Selection in Innovative Training for College Students
}

\author{
H.Y. WANG \\ Faculty of Resource and Safety Engineering, China University of Mining and Technology (Beijing), Beijing, \\ China
}

\begin{abstract}
Scientific and technological innovation is one of the development strategies put forward by the Chinese Government. Being the hard core of talent cultivation in science and technology, college shoulders the task of cultivating innovative talents, which is one of the primary missions at present. In this paper, detailed analysis and discussion have been conducted on the implementing principle, subject selection source, implementation strategy and effect evaluation of the innovative training for college students, in order to better improve the innovation ability of students and promote the development of their academic competence and scientific research ability. In addition, analysis on issues deserves attention in the follow-up training, in accordance with the actual effect of subject selection, has also been mentioned in this paper.
\end{abstract}

KEYWORD: Innovative Training; Subject Selection; Innovation; Implementation Strategy; Effect Evaluation

\section{INTRODUCTION}

It is stressed in the report for the 18th National Congress of CPC that: "Scientific and technological innovation provides strategic support for raising the productive forces and boosting the overall national strength, and we must give it top priority in overall national development." The support for scientific and technological innovation is derived from the innovation-type talent team. College students are important holders and heirs of science and technology in China. Therefore, it is of great significance to provide college students with innovation education.

Being the key component in the "innovation teaching round" during the undergraduate studies, innovative training is also an important carrier for effectively improving the quality of talent cultivation. Subject selection is the beginning of scientific study, in which the subject selection is of vital importance. Being the first found in innovative training, subject selection plays an essential role in guaranteeing the training effect, as well as the smooth implementation of innovative activities. The level of subject selection is an important symbol in weighing the research ability of the researchers, and its process, in fact, is also a significant step (Gui S. Z. \& Yang X. P (2007)) for improving the research ability of researchers and enabling them to move towards professionalization.

\section{THE IMPLEMENTING PRINCIPLES OF SUBJECT SELECTION IN INNOVATIVE TRAINING FOR COLLEGE STUDENTS}

Subject selection in innovative training should execute the implementing principles of "being interest-driven, self-conducted experiments, focusing on the process, and combining with the expertise".

\subsection{Interest-driven}

Interest is of great significance in individual practical activities, in which it enables the individuals to focus the attention and fall into a pleasant and nervous psychological status, thus concentrating on obtaining knowledge and innovatively complete the current activity. Subject selection in innovative training must follow the principle of "being interest-driven", namely that the students must show great interest in the scientific research or creative innovations, and complete the experiment and research under the guide of tutor. In other words, the subject the student selected must be able to stimulate his autonomy and initiative in the investigation. Einstein once said: "interest is the best teacher" (Zhang T. \& Chen F. (2007)). Professor Ding Zhaozhong, a famous Chinese scholar in America, once said: "as for all the scientific researches, the most important is whether you show interest in the job you take up or not ..." Hence, the subjects selected by students must be in the fields (or 
direction) they show interest in. Only in this way can they overcome the difficulty, challenge themselves and be persistent in the whole process of scientific research, thus achieving the purpose of learning by combining with innovative practice in scientific researches.

\subsection{Self-conducted experiments}

Self-conducted experiments require that the students involved should design the experiment, complete the experiment and management the experiment all by themselves. Autonomy is the character of human and the core of human quality. It is put forward in the Constructivism Theory (Li X. W. (2013)) that autonomous learning is, in fact, a kind of learning without cognitive monitoring. It is also the process for students to adjust their learning strategy and effort level in line with the requirements for learning ability and learning tasks. Autonomy requires self consciousness and reflection in the questions, including why do we learn, what should we learn and how to learn, etc. In the process of subject selection, self-conducted experiment actually requires that the subjects selected must enable the students to complete the whole research process by themselves in the light of their own level and ability. The students should follow the principle of "data can be obtained, task can be completed and the results can be predicted" in the process of selection and completion, and then improve their autonomous ability and innovative ability in finding the problem, analyzing the problem and solving the problem in course learning, discipline development, as well as in social life.

\subsection{Focusing on the process}

Zhang Ruimin, CEO in the Haier Group, once said: "it is rather complicated to complete every simple thing, and similarly, you will be unusual if you are able to complete every workday concerns." Despite the fact that it is most perfect summary for enterprise delicacy management, it is also applicable in the subject selection in innovative training and the practice process of scientific researches. Innovative subject selection and the follow-up practice process should pay more attention to the implementation process of innovative training, and lay emphasis on gains of the students in innovative thinking and innovative practice.

\subsection{Combining with the expertise}

The students should be encouraged to take active part in practical activities, combining with their expertise and starting from their own specialty and interest, and put forward their own views in the training process of exploration, research and innovation. Take the students in Safety Engineering for example, their major covers a large scale, so assessment can be conducted on disaster prevention and control for mines and underground construction, transportation, factories, real estate, commercial buildings and surface structures, as well as engineering and ventilating, air conditioning, safety monitoring and control, safety principles, safety system engineering, safety supervision and management, etc., and scientific research tasks suitable for the students can be selected. However, vague and general subject researches should be avoided, while research contents in method innovation and theoretical innovation should be introduced to engineering practice and field application as much as possible.

\section{SOURCE AND IMPLEMENTATION STRATEGY OF INNOVATIVE TRAINING TOPIC SELECTION OF COLLEGE STUDENTS}

Scientific researches can be generally divided into basic research, application research and development research. The researches targets in three aspects are different. Basic research is the new understanding of nature or society. It aims at finding out new rules and principles. Application research makes use of certain rules to put forward some new technologies, skills and methods. And the development research is the realization of the specific function or effectiveness, in order to create a product to meet the need of the market. For college students, they could choose anyone of the three researches combined with the specific situation of the profession. In campus, there are various topic selections provided, including subprojects in the teacher's scientific researches, and the projects of subject contests, and innovative experiment projects in the lab , training or practice base, and innovative projects, such as invention, creation and design, and professional social surveys and researches, and other projects with theoretical and practical values.

In the course of the innovative training, it's better to take the tutor system principle, that is conducting scientific research training by the students independently under teacher's leadership. The students could make joint consultation with the tutor inn the six topic selections to determine the professional scientific research subject and research content that are to be carried out. In the process of implementation, the following strategies are recommended.

(1) Understand the research trends. The research trends means the development trends and development tendency of the science and technology involved in the subject at home and abroad. Before a student chooses a subject, deeply investigation and 
argumentation of the selected subject shall be finished, including the development status of similar topics, and the information about this at home and abroad. In this way, the topic selection can be of innovation and basis of topic selection can be sufficient.

(2) Grasp the research scope of topics selection. It is the key of ensuring the smooth implementation of the following-up training to scientifically grasp of the research scope of topics selection. The principles of the scope of topics selection are as follows (Guo X. H. (2004)). Firstly, in basic research, first place should be given to the researches with important scientific significance or important prospects. Secondly, application research gives priority to the researches with significant economic benefits and social benefits. There is no doubt that the basic research is the emphasis of topic selection and research. In addition, application research plays a very important role in solving the major problems in the development of society and economy. Therefore, the application research is also the major task in the scientific research activities of university students.

(3) Formulate specific measures with strong feasibility. It's the key to achieve the expected target that whether the topics are reasonable, that the technical route is right and the measures are effective. When a student choose his topic, he shall make a detailed plan on the research objectives, implementation steps, the experiment content, the key technology and the expected target. He shall accurately grasp the situation of experimental equipment and expenditure. The formulated plan and expected target cannot be separated from reality, and the scientific research budget shall be reasonable.

On the premise of implementation strategies mentioned above, the form of teamwork combined with tutor's guidance can be adopted in principle. In terms of number of members in the team, large groups could produce a larger number of decision schemes with higher quality according to relevant theoretical research results (Peter W. \& Amos T. (1993)). Generally speaking, the members have a high level of involvement, and it's easier to reach consensuses in a team with less than 5 members. Hence, it's better for a project team to work together in a team of about 5 people. In the view of topic selection source, subsidies should be firstly given to scientific research projects of faculty advisors or the innovative training projects of longitudinal topic selection. As for the selection of tutor, the tutor shall be at lest associate professor or above in principle.

\section{THE EFFECT EVALUATION SYSTEM AND EFFECT ANALYSIS FOR SUBJECT SELECTION IN INNOVATIVE TRAINING}

Establishing the evaluation index system is the foundation for comprehensive evaluation. Evaluation index system is not only the link between the evaluator and the evaluated, but also the bridge linking the evaluation methods and the evaluated. Only by scientific and reasonable evaluation index system can scientific and fair evaluation conclusions be gained. The effect evaluation should take the effectiveness and fairness of the evaluation, as well as the objective authenticity of the evaluation results into consideration. Based on the principle, the Author put forward the evaluation index system for subject selection in innovative training by referring to relevant documents, researches and expert consultation (Figure1.).

(1) The attitude towards subject selection in innovative training. It includes the degree of involvement, initiative and the recording condition of activities.

The degree of involvement mainly refers to the inspection on the attendance for collective activities and research activities arranged by the tutor, as well as on the working conditions of project research. The initiative and autonomy focus on whether the students will actively and initiatively express themselves, assume the project research and communicate with the teachers, tec. The recording condition of activities is determined by whether the recording frequency is up to the standard specified by the tutor and whether the contents are complete, rigorous and standardized.

(2) Knowledge learning. It includes the degree of reference, analysis and utilization in documents, as well as the degree of learning the expertise and relevant knowledge, etc.

The degree of reference, analysis and utilization in documents focuses on the ability in document screening, sorting out, analyzing and utilizing, as well as whether the frequency of referring to documents meet the specified requirements, and whether the sorting is up to standard. The degree of learning the expertise and relevant knowledge is mainly the inspection on knowledge quantity and how much has been grasped by the students, as well as whether the students have actively followed the tutor's requirements, or initiatively learned knowledge in relevant subject area.

(3) Comprehensive ability cultivation. It includes practical ability, innovation ability, research ability and expression ability.

The practical ability is mainly for investigating how much has been grasped by students in the experiment regulations and technical specification, the reasonability of the experiment design, as well as the condition of phased objectives. The innovation ability concentrates on whether the students have independent views and the ability of discovering and analyzing potential problems, the rationalization proposals on the research program, and whether the students are able to explore the doubtful points and 
difficulties in the research. The research ability fastens on whether the students have mastered the scientific methods, including deducing, concluding and integrating, whether they are able to effectively use the document literature, and whether the ability of collecting, sorting out and analyzing the experimental data meet the requirements. The expression ability is bent on whether the reporting for subject selection is up to standard, whether the words are expressed correctly and smoothly, and whether the report is clear and normative, etc.

(4) Cultivation of comprehensive quality, which includes team awareness, team spirit, responsibility and scientific spirit

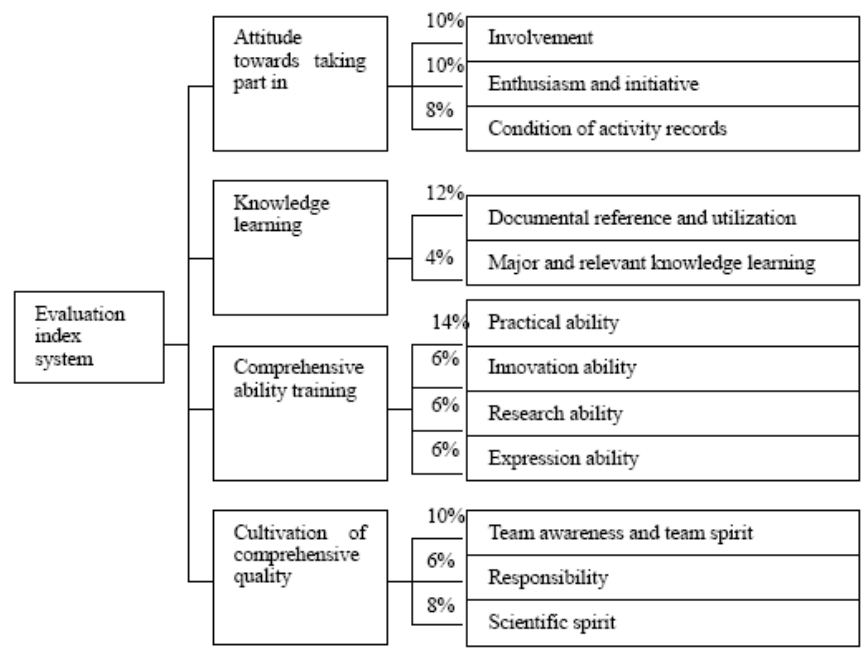

Figure 1. Evaluation index system for subject selection in innovative training for college students.

Team awareness and team spirit mainly tests whether the students have awareness of mutual assistance and complementation, consciousness of general situation in completing the project objective, quality of respecting others and being inclusive, and whether they can initiatively communicate, learn and exchange views with their tutors. Responsibility places emphasis on whether the students can actively complete the assigned tasks, undertake other tasks, as well as the responsibility of achieving the project objective. For scientific spirit, significance is attached to whether the data needed is reliable, and whether the experimental reasoning, data processing and analysis are adequate in preciseness, as well as the academic integrity, etc.

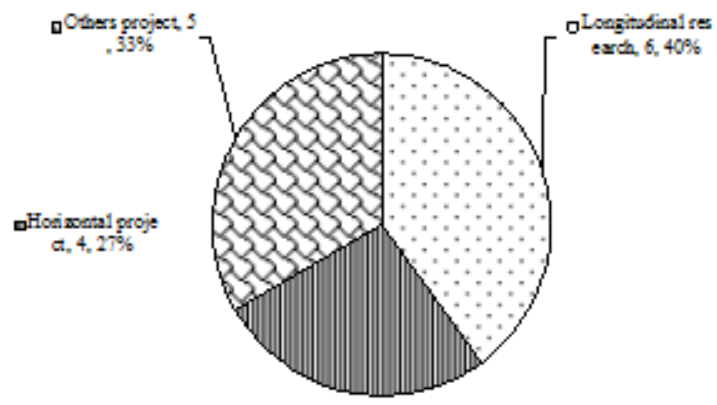

Figure 2. Source distribution of the subject.

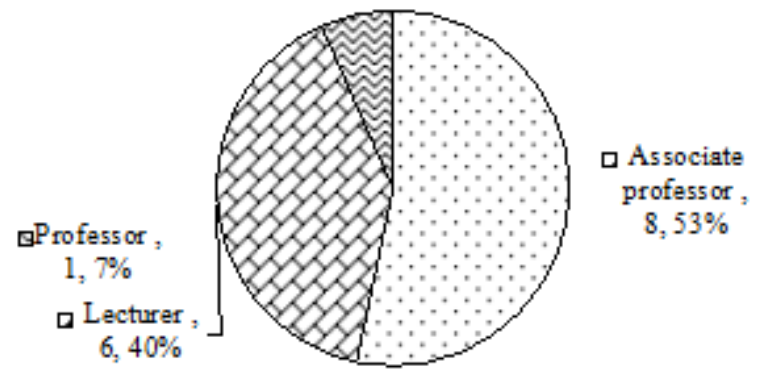

Figure 3. Tutors distribution

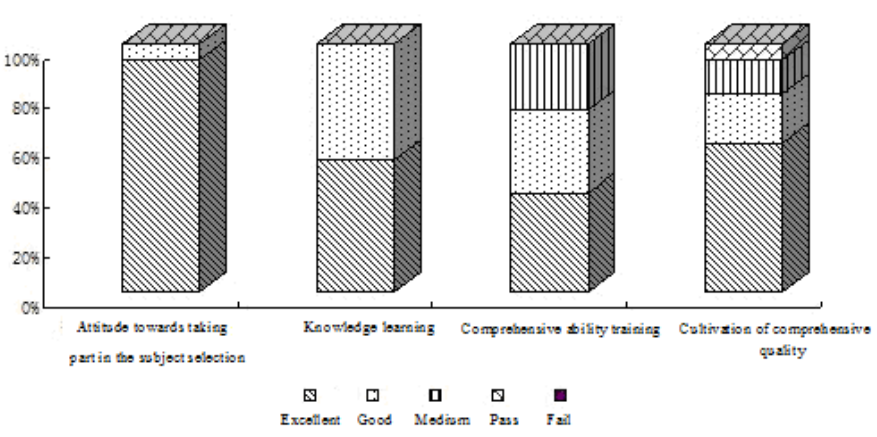

Figure 4. Performance distribution of each subject in the scientific selection of the students.

Based on the above-mentioned index system, each index will be given certain weight in line with the characteristics of different majors and colleges, and then the index with certain weight will be used for evaluating the effect of innovative training. The Author, after investigation and analysis on the profession he takes up, adopted the weight allocation shown in Figure1, which was used in the evaluation.

Evaluation on subject selection in innovation training was, taking advantage of the established evaluation index system, conducted in the students, who enrolled in 2011, in Safety Engineering of China Mining University (Beijing). There are 70 students, divided into 15 groups with an average of 4-5, taking part in the subject selection, and 15 tutors will be responsible for guiding the students. The source of subject selection (Figure 2.), in which longitudinal subject accounts for $40 \%$, enterprise horizontal cooperation represents $27 \%$, and others make up 33\%, has high combination degree of major and scientific research project. For tutors (Figure 3.), those at a level above associate professor account for $93 \%$. So, we can see that the scientificity and practicability of the scientific subject selection, as well as the quality of tutors, are all well guaranteed.

15 groups of students completed the report for scientific research after conducting the subject selection in line with the above-mentioned methods, and comprehensive evaluation will be conducted in four aspects, including attitude towards taking part in the subject selection, knowledge learning, comprehensive ability training and cultivation of comprehensive quality, after they finished the thesis defense and query. Distribution of their performance is shown in Figure 4. The comprehensive 
performance of the students, which has achieved the desired effect, is good. However, there are still some common problems, which deserve attention in the follow-up training:

(1) Since the students involved in the subject selection are in their sophomore year, they are significantly short in professional knowledge learning, especially in combining with major course learning and professional knowledge expanding, which should be enhanced with the help of tutors in the follow-up training;

(2) Similar to the above-mentioned, the cultivation of innovation ability in the phase of subject selection has achieved a good opportunity for practice. However, the research ability and expression ability should be strengthened in the process of follow-up innovative training;

(3) Some students have not fully comprehended the connotation of scientific spirit yet. Hence, perfection and improvement should be guaranteed in the follow-up innovative training, to enable the students to know that scientific spirit is an important guarantee for accomplishing the scientific research tasks.

\section{CONCLUSIONS}

For college students, innovative training is not only an important round for the cultivation of innovation ability in scientific research, but also an important content which conforms to the national technological innovation strategy. In the process of subject selection, scientific contents, which are beneficial to the cultivation of innovation ability, with high feasibility and high progressiveness should be adopted in the research, and scientific and reasonable implementation strategy, as well as an evaluation system should, at the same time, be established.

\section{REFERENCES}

[1] Gui S. Z. \& Yang X. P. 2007. The principles and ways of educational scientific research topic selection. Teaching and management 1(3): 60-61.

[2] Zhang T. \& Chen F. 2007. Cultivation of College Students' scientific research and innovation ability. Journal of Anhui Vocational College of Electronics \& Information Technology 6(30): 9-10.

[3] Li X. W. 2013. Medical colleges English teaching under the view of constructivism learning theory. Soft Science of Health 27(1): 24-25.

[4] Guo X. H. 2004. Analysis of scientific research topic selection for College Students. China Adult Education 2: 48-49.

[5] Peter W. \& Amos T. 1993. An axiomatization of cumulative prospect theory. Journal of Risk and Uncertainty 7(2): 147-176. 